\title{
Estudo da estrutura da crosta na região da Bacia do Parecis usando eventos profundos.
}

Matheus Figueredo de Paulo, George Sand França, Diogo F. Alburquerque, Giuliano S. Marotta

Observatório Sismológico-Instituto de Geociências, UnB.

Copyright 2016, SBGf - Sociedade Brasileira de Geofísica

Este texto foi preparado para a apresentação no VII Simpósio Brasileiro de Geofísica, Ouro Preto, 25 a 27 de outubro de 2016. Seu conteúdo foi revisado pelo Comitê Técnico do VII SimBGf, mas não necessariamente representa a opinião da SBGf ou de seus associados. É proibida a reprodução total ou parcial deste material para propósitos comerciais sem prévia autorização da SBGf.

\section{Resumo}

Neste projeto, foram utilizadas eventos profundos com objetivo é de estimar as espessuras crustais e a razão $\mathrm{Vp} / \mathrm{s}$ nas estações na Região Norte e Centro-Oeste do Brasil, utilizando o método da Função do Receptor.. A Função do Receptor é composta por séries temporais obtidas através de registros sísmicos em estações triaxiais que mostram a resposta relativa de uma estrutura geológica presente no interior da Terra. Este método utiliza os registros das ondas $P$ de telessismos que atingem a base da crosta com um ângulo próximo à vertical $\left(\theta<40^{\circ}\right)$ logo abaixo de uma estação sismográfica. Além disso, utiliza os registros da conversão da onda $\mathrm{P}$ em onda S (fase Ps) ao atravessar uma descontinuidade e das reflexões múltiplas (PpPhs e PpPhs+PpShs). Através da deconvolução da componente horizontal pela vertical, obtém-se a Função do Receptor, que apresenta um pico maior correspondente à onda $\mathrm{P}$ direta, seguido pelo pico da onda $\mathrm{P}$ convertida na descontinuidade de Moho (Ps) e pelas fases múltiplas. Foram selecionados 16 eventos profundos com magnitudes maior que 4,0 mb. A inspeção visual dos eventos foi realizada com o programa SAC (Seismic Analysis Code, Goldstein \& Snoke, 2005) e a deconvolução no domínio do tempo. O cálculo de espessura crustal e razão $\mathrm{Vp} / \mathrm{Vs}$ foi realizado por meio do software HK-Stacking, que faz o empilhamento de fase por peso (grau de certeza da chegada das fases P, Ps e múltiplas) e nele foi inserida a velocidade média da onda $P$ na crosta $(6,4 \mathrm{Km} / \mathrm{s})$ como parâmetro inicial. Os valores de espessura crustal e razão $\mathrm{Vp} / \mathrm{Vs}$ obtidos teve uma variação entre 37 a 42 km e Vp/Vs 1.70 a 1.88.

\section{Introdução}

A sismologia pode ser definida como um método indireto para obtenção de informações sobre a estrutura interna do planeta utilizando informações sobre os diferentes comportamentos de ondas sísmicas em variadas regiões da Terra. A partir destas informações os pesquisadores conseguiram determinar zonas de grandes variações de propriedades químicas e físicas. Uma dessas zonas conhecida como descontinuidade de Moho (Crosta Manto) foi descoberta por Andrija Mohorovicic em 1909. Nessa região há um contraste relevante na velocidade de propagação das ondas sísmicas. A função do receptor é um método utilizado na sismologia para obtenção de informações do meio onde a onda se propaga, mais especificamente a descontinuidade de Moho, podendo assim ser feita uma estimativa da razão entre as velocidades das onda $\mathrm{P}$ e $\mathrm{S}$ e espessura da crosta na região estudada e a razão entre $\mathrm{Vp} / \mathrm{Vs}$. Neste trabalho foi utilizado o método da função do receptor utilizando eventos profundos com a finalidade de verificar a qualidade dos dados finais quando comparados ao uso do mesmo método utilizando terremotos em quaisquer profundidades, além de realizar a medição da espessura da crosta da Terra nas regiões estudadas.

\section{Função do Receptor}

A Função do Receptor é um método direto de extrair informações a respeito da crosta e do manto superior por meio de ondas sísmicas de terremotos distantes registradas em estações triaxiais (Langston e Ammon, 1991). O princípio físico do método baseia-se no fato de que uma onda sísmica primária $(P)$, ao mudar de um meio de maior para um de menor velocidade, tem parte de sua energia convertida em onda $S$ (fase Ps), gerando também múltiplas reflexões (fases Ppps e Psps+Ppss), Para que haja um registro preponderante das fases horizontais de interesse, é necessário rotacionar o sismograma na direção do evento, mudando do sistema de coordenadas convencional de aquisição da estação (Vertical, Norte-Sul e Leste-Oeste) para o sistema ZRT (Vertical, Radial e Transversal).

Com isso, teremos um registro da onda $\mathrm{P}$ na direção vertical e da Ps na direção radial do sistema ZRT. Em tese, não deve haver registro na componente transversal, haja vista que esta é perpendicular à radial e, portanto, não há resultante em outras direções. Para que o evento tenha utilidade na obtenção da FR, a onda $\mathrm{P}$ deve atingir a base da estação com um ângulo de incidência maior do que $40^{\circ}$. Para tal, foram selecionados telessismos ocorridos em distâncias a partir de $30^{\circ}$. Eventos com distâncias acima de $100^{\circ}$ não são registrados devido ao efeito de zona de sombra.

A FR é obtida pela deconvolução da componente vertical pela radial, que isola a resposta do receptor e o resultado é a assinatura das fases convertidas e múltiplas reflexões que indicam a estrutura da crosta subjacente à estação sismográfica (Langston, 1979; Ammon, 1991). Com os valores de tempo de chegada das ondas P, Ps e múltiplas (PpPms), é possível calcular a espessura crustal $(\mathrm{H})$ e a razão $\mathrm{Vp} / \mathrm{Vs}$ por meio das equações (1) e (2).

$$
\frac{V p}{V s}=\sqrt{\left(1-p^{2} V_{p}^{2}\left[2\left(\frac{\Delta_{P s}}{\Delta_{P p P m s}}\right)+1\right]^{2}+p^{2} V_{p}^{2}\right)}
$$




$$
H=\frac{\Delta_{p s}}{\sqrt{V_{s}^{-2}-p^{2}}-\sqrt{V_{p}^{-2}-p}}(2)
$$

Onde:

$\triangle$ Ps é a diferença de tempo entre as fases P e Ps;

$\triangle$ PpPms é a diferença de tempo de chegada das fase múltiplas;

p é o parâmetro de raio;

$\checkmark p$ é a velocidade da onda $P$;

Vs é a velocidade da onda $S$.

\section{Processamento de Dados}

Os dados utilizados para realizar a FR (Tabela 1) são referentes aos terremotos profundos $(\sim 600 \mathrm{~km})$ que ocorreram a partir do dia 24 de novembro de $2015 \mathrm{com}$ epicentros localizados na região de fronteira do Brasil com o Peru, e um evento com epicentro localizado na região central da Bolívia.

Tabela 1: Terremotos utilizados para realizar a Função do Receptor

\begin{tabular}{|l|l|l|l|l|l|}
\hline Data & Hora UTC & Lat $\left(^{\circ}\right)$ & Long $\left(^{\circ}\right)$ & Mag & Prof $(\mathbf{K m})$ \\
\hline $24 / 11 / 2015$ & $18: 10: 07$ & -10.48 & -70.95 & 4.0 & 586,7 \\
\hline $24 / 11 / 2015$ & $22: 45: 38$ & -10.548 & -70.904 & 7.6 & 600,6 \\
\hline $24 / 11 / 2015$ & $22: 50: 54$ & -10.047 & -70.023 & 7.6 & 611,7 \\
\hline $24 / 11 / 2015$ & $23: 44: 14$ & -10.557 & -70.990 & 4.6 & 595,1 \\
\hline $24 / 11 / 2015$ & $23: 55: 20$ & -10.287 & -70.872 & 4.1 & 618,8 \\
\hline $25 / 11 / 2015$ & $00: 28: 16$ & -11.033 & -70.848 & 4.7 & 597,1 \\
\hline $25 / 11 / 2015$ & $09: 26: 23$ & -8.537 & -71.375 & 4.6 & 641,9 \\
\hline $25 / 11 / 2015$ & $16: 19: 24$ & -9.847 & -71.271 & 4.3 & 630,5 \\
\hline $25 / 11 / 2015$ & $18: 47: 55$ & -10.367 & -70.637 & 4.3 & 648,4 \\
\hline $26 / 11 / 2015$ & $05: 45: 18$ & -9.191 & -71.288 & 6.7 & 599,4 \\
\hline $26 / 11 / 2015$ & $06: 01: 23$ & -9.27 & -71.27 & 4.8 & 606,0 \\
\hline $26 / 11 / 2015$ & $13: 42: 24$ & -9.795 & -71.254 & 4.9 & 609,6 \\
\hline $27 / 11 / 2015$ & $00: 52: 54$ & -9.139 & -71.154 & 5.1 & 609,4 \\
\hline $29 / 11 / 2015$ & $10: 41: 32$ & -10.173 & -71.181 & 4.2 & 625,6 \\
\hline $03 / 12 / 2015$ & $23: 29: 48$ & -10.270 & -71.399 & 4.0 & 622,9 \\
\hline $14 / 01 / 2016$ & $03: 25: 28$ & -19.826 & -53.285 & 6.1 & 582,4 \\
\hline
\end{tabular}

As estações utilizadas para realizar a FR (Figura 2) são da rede sismográfica Brasileira (RSBR) e da rede temporária do Parecis, financiada pelo CNPq (Universal 2014), emprestadas pelo Pool de Equipamentos e localizadas nos estados da região norte do país, e da parte oeste e norte do estado de Mato Grosso que estão sobre responsabilidade do Observatório Sismológico da Universidade de Brasília (UnB).

Para realizar o processamento de dados foi utilizados os códigos abertos do Herrmann (2013) e para a estimativa da espessura e $\mathrm{Vp} / \mathrm{Vs}$, usamos o programa HK-stacking, baseado no Zhu e Kanamori (2000). As FRs geradas foram analisadas para verificação da qualidade do resultado. A figura 2 demonstra o FR do evento de 24/11/2015 ás 22:45:38.
As FRs com alta razão-sinal ruido foram usadas no HKstacking para gerar as estimativas de espessura da crosta e razão $\mathrm{Vp} / \mathrm{Vs}$. O parâmetro utlizado para $\mathrm{Vp}$ foi de 6,4 e os pesos de 0,7 0,2 e 0,1 para pesos de Ps e multiplas, respectivamente (Zhu \& Kanamori, 2000).

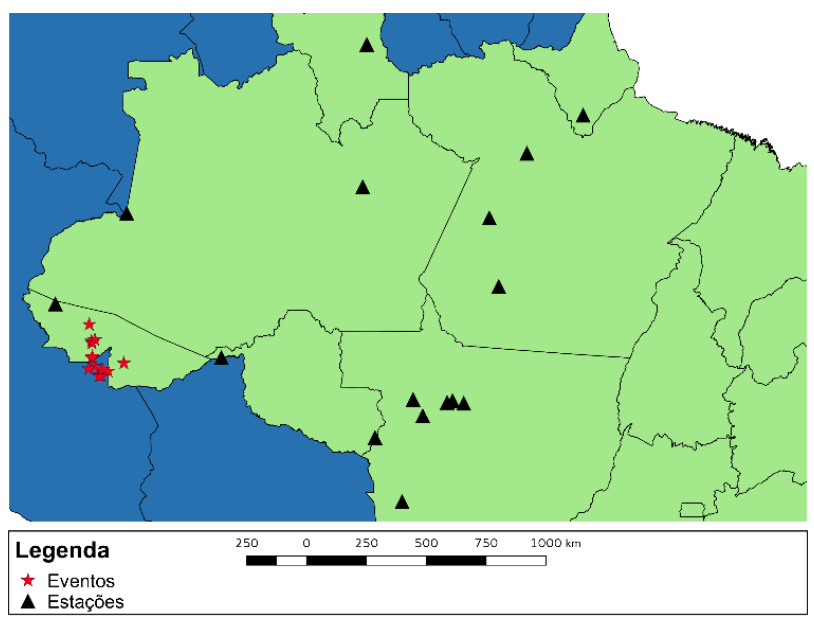

Figura 1 : Mapa com a localização das estações sismológicas e eventos utilizados.



Figura 2: Função do receptor do evento de 24/11/2015 ás 22:45:38 para cada estação.

\section{Resultados}

Ao realizar a FR foi possível perceber que algumas estações apresentaram alguns problemas provenientes de mal funcionamento da estação ou de orientação, que foram descatadas nesse trabalho.

Os terremotos abaixo de 4,5 de magnitude também apresentaram problemas, neste caso provenientes da baixa energia que chegava até os equipamentos, tornando assim os dados inviáveis para realizar a FR. Outros eventos não puderam ser utilizados para realizar.

Os resultados da razão $\mathrm{Vp} / \mathrm{Vs}$ e espessura da crosta obtidos através da utilização do software HK-Stacking, (Figura 2) demonstram bons resultados em muitas estações, porém algumas estações como PAR3 e PAR6 não apresentaram nenhum resultado, provavelmente provocado por dados muito ruidosos impedidndo a aplicação do método. 


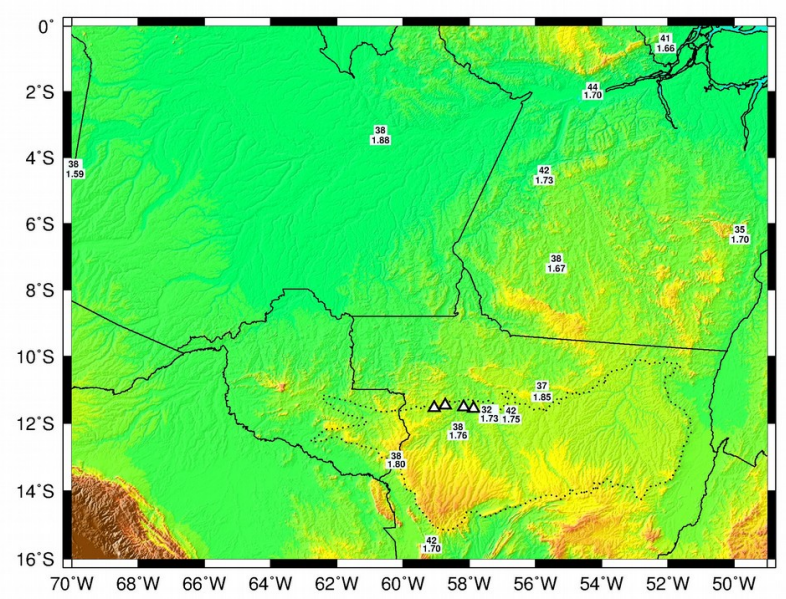

Figura 2: Resultado do Hk-Stacking demonstrando as razões $V p / V s$ e a espessura da crosta

\section{Discussão e Conclusões}

Os resultados preliminares mostram uma crosta mais espessa no Norte 38-44 km, com Vp/Vs 1.67-1.73 em sua maioria. Já na região da bacia do Parecis, a dispersão dos dados é maior com grande contraste de espessura e $\mathrm{Vp} / \mathrm{Vs}$, o que indica que as estimativas podem está comprometida, na hipótese de erro em uma das estações, a crosta tem espessura entre $37-42 \mathrm{~km}$ e $\mathrm{Vp} / \mathrm{Vs}$ dentro da bacia 1.73-1.76, apresentando um carater mais cratônico e dois valores com $\mathrm{Vp} / \mathrm{Vs}$ alto, na parte norte e oeste da Bacia. Na parte Su, apresenta um espessura de $42 \mathrm{~km}$ e Vp/Vs menor que na bacia.

As estimativas de espessura estão consistentes com os estimados por Assumpção et al., (2013) e Pavão et al., (2012), entretanto esses resultados apresentam uma margem de erro considerável que não permite ainda ter um comparação conclusiva. A grande importância desse trabalho é que o uso de eventos profundos tem resultados similares aos obtidos pela FR convencional.

\section{Agradecimentos}

Aos Técnicos e Alunos de Campo, Daniel Linhares e Paulo Alves pela implementação da rede temporária. Ao Pool de Equipamentoos, pelo empréstimo dos equipamentos, ao CNPq através do edital Universal 2014, processo 456560/2014-9 e GSF agradece ao CNPq/PQ.

\section{Referências}

AMMON, C. J., The isolation of receiver effects from teleseismic P waveforms, Bull. Seism. Soc. Am., 81, 2504-2510, 1991.

ASSUMPÇÃO, M. BIANCHI, M., JULIÀ, J., DIAS, F. L., FRANÇA, G. S., NASCIMENTO,R., DROUET, S., PAVÃO, C. G., ALBUQUERQUE, D. F. e LOPES, A. E. V. Crustal thickness map of Brazil: Data compilation and main features. Journal of South American Earth Sciences 43, p. 74-85, 2013.
GOLDSTEIN, P. \& A. SNOKE, 2005. "SAC Availability for

the IRIS Community", Incorporated Research Institutions for Seismology Data Management System Electronic Newsletter.

LANGSTON, C. A. Structure under Mount Rainier, Washington, inferred from teleseismic body waves. J. Geophys. Res. Vol. 84 (B9), p. 4.749, 1979.

HERRMANN, R. B. (2013) Computer programs in seismology: An evolving tool for instruction and research, Seism. Res. Lettr. 84, 1081-1088, doi:10.1785/0220110096

PAVÃO, C. G., FRANÇA, G. S., MAROTTA, G. S., MENEZES, P. H. B. J., NETO, G. B. S. \& ROIG, H. L. Spatial Interpolation Applied a Crustal Thickness in Brazil. Journal of Geographic Information System 4, p. 142-152, 2012.

ZHU, L., AND H. KANAMORI, 2000. Moho depth variation in southern California from teleseismic receiver functions, J. Geophys. Res., 105 , 2969-2980. 